\title{
$028-029$ \\ Noticias y comentarios \\ Avances en el programa de cooperación entre el IAPH y el CENCREM de Cuba
}

Presentamos a continuación un resumen de las actividades realizadas en el último trimestre de 2003 en el marco del programa de cooperación plurianual entre el Instituto Andaluz del Patrimonio Histórico, IAPH, y el Centro Nacional de Conservación, Restauración y Museología, CENCREM, de Cuba. Este proyecto forma parte del Programa de Cooperación Internacional de la Junta de Andalucía financiado a través de la Consejería de Presidencia.

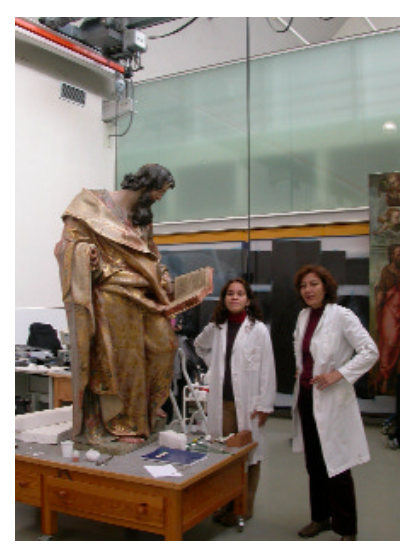

A mediados del mes de septiembre Miriam Duverger, Subdirectora de Bienes Muebles del CENCREM, se incorporó al Centro de Intervención del Instituto, en cuyos talleres de restauración pudo conocer la metodología seguida por el IAPH en los proyectos de intervención de retablo, lo que le fue de gran utilidad para afrontar el proyecto de restauración de la Iglesia de Guanabacoa que emprendemos en colaboración entre el CENCREM y el IAPH. Para ello se realizaron igualmente visitas técnicas a los retablos de la Iglesia de la Caridad, Convento de Madre de Dios, Capilla Real de Granada, Iglesia del Sa-

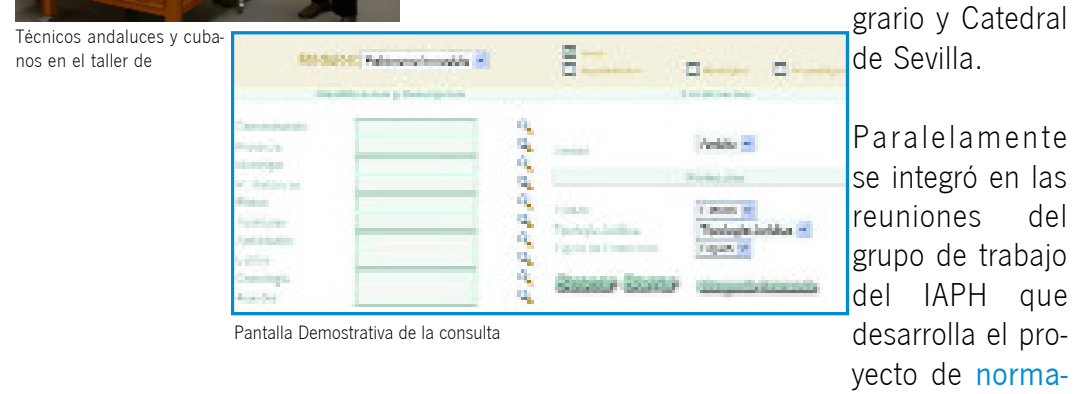

lización de los procedimientos de intervención en bienes muebles, formado por técnicos de los Centros de Documentación e Intervención, con el objeto de aportar su visión desde la metodología y procedimientos utilizados en el CENCREM. En estos momentos el CENCREM trabaja para normalizar sus procedimientos de intervención y poder desarrollar una aplicación informática conjunta.

Por otra parte durante el mes de noviembre contamos con la estancia en el IAPH de tres técnicos del Consejo Nacional de Patrimonio Cultural, CNP, del Ministerio de Cultura de la República de Cuba: María Teresa Iglesias, asesora de la Presidencia del CNP, Gladys Collazo, Jefa del Departamento de Informática del CNP, y Osvaldo Ramos, especialista de la Vicepresidencia de Monumentos del CNP.

Para ellos se diseñó un completo programa de estancia que incluia sesiones de trabajo en el IAPH junto con visitas a centros especializados de la Consejería de Cultura, como el Centro de Arqueología Subacuática, Dirección General de Bienes Culturales, Dirección General de Instituciones de
Patrimonio, Servicio de Informática y otros de especial interés para los contenidos del proyecto como el Instituto de Cartografía de Andalucía, ICA.

En el Centro de Documentación del IAPH tuvieron la ocasión de analizar el Sistema de Información del Patrimonio Histórico en Andalucia profundizando en las bases de datos gráfica, ciudades históricas, patrimonio inmueble, arqueología, bienes muebles y el proyecto de catalogación de patrimonio inmaterial. Por su parte en el Servicio de Protección de la DG de Bienes Culturales conocieron el funcionamiento y sistematización del Catálogo General del Patrimonio Histórico de Andalucía y en el Servicio de Museos de la DG de Instituciones conocieron la base DOMUS para la gestión de las colecciones. En el Servicio de Informática pudieron conocer el proyecto de sistema integrado de bases de datos de la Consejería de Cultura además de tratar las posibilidades de adaptar estos sistemas a las necesidades del Consejo Nacional de Patrimonio cubano.

A lo largo de este último trimestre se ha podido igualmente ir concretando varias de las actividades previstas en el plan plurianual para la siguiente fase del programa. Así, entre las acciones destacadas para el 2004, podemos señalar la realización de diversas actividades formativas en Cuba, como un taller para técnicos que vinculen el desarrollo local con la puesta en valor de los recursos patrimoniales y el turismo, un seminario sobre la aplicación en la documentación e intervención del patrimonio de los Sistemas de Información Geográfica o un curso sobre técnicas fotográficas y radiológicas para la intervención del patrimonio mueble.

Esperamos que este programa de cooperación basado en el intercambio reciproco de métodos, criterios de actuación y conocimientos para la gestión y conservación integrada del patrimonio cultural continúe desarrollándose con el mismo interés para los profesionales e instituciones cubanas y andaluzas implicadas.

Pilar Tassara Andrade

Área de Cooperación

IAPH- EPGPC 